\title{
Primary Multiple Simultaneous Intracerebral Hemorrhages between 1950 and 2013: Analysis of Data on Age, Sex and Outcome
}

\author{
Denchai Laiwattana $^{a} \quad$ Bussara Sangsawang $^{b} \quad$ Nucharee Sangsawang $^{\text {b }}$ \\ a Neurosurgery Department, Bangkok Hospital Trat, Trat, and bFaculty of Nursing, \\ Srinakharinwirot University, Bangkok, Thailand
}

\section{Key Words}

Multiple simultaneous intracerebral hemorrhages · Spontaneous intracerebral hemorrhage · Primary intracerebral hemorrhage $\cdot$ Secondary intracerebral hemorrhage

\section{Abstract}

Background: Primary multiple simultaneous intracerebral hemorrhages (MSICHs) are quite rare. Although occasional reports have been found, there have been no systematic reviews. The published case reports and case series contain overlapping data, leading to erroneous information about MSICHs. This is the first extensive review of accessible studies published in English on MSICHs. Our primary objective was to analyze the demographic data on age, sex, outcome and prognosis with regard to primary MSICHs. Summary: A PubMed search without language restriction for articles with results from human studies and registered between January 1950 and September 2013 yielded 677 articles. The following inclusion criteria were applied: (1) reported case(s) or case series on primary MSICHs; (2) text partly or fully in English, and (3) text contains identifiable data on age, sex and outcome of patients. A total of 24 articles met all the inclusion criteria. The reference lists of these 24 articles were inspected for additional relevant articles, which yielded another 20 articles. In all, 248 cases were identified; 143 cases were excluded for various reasons: 52 duplicate cases, 18 cases of multiple nonsimultaneous intracerebral hemorrhages, 25 cases of secondary MSICHs, and 48 cases with incomplete data on age, sex and outcome. The remaining 105 cases were analyzed. MSICHs were found to be more common in bilateral cases (53.33\%): there were bilateral basal ganglia hemorrhages (33.33\%), bilateral thalamic hemorrhages (18.10\%), bilateral lobar hemorrhages $(0.95 \%)$ and bilateral cerebellar hemorrhages $(0.95 \%)$. Nonbilateral MSICHs were found in $46.67 \%$ of the cases. The hematomas were commonly distributed in the basal ganglia (45.83\%), thalamus (30.56\%) and cerebellum (10.19\%). MSICHs were more frequently encountered in males (60.95\%; average age: $59.13 \pm 12.49$ years). The average age of the female patients was 
higher ( $63.89 \pm 13.11$ years). Patients with primary MSICHs had a survival rate of $56.20 \%$. There was a favorable outcome of primary MSICHs in $18.10 \%$ of all the cases, the highest proportion of which was in the nonbilateral MSICH group. The remaining $38.10 \%$ had unfavorable outcomes. Death occurred in $43.80 \%$ of all cases, the highest proportion being found in the bilateral basal ganglia hemorrhage group. Primary MSICHs share features with solitary intracerebral hemorrhage regarding age, sex, and the location and distribution of hematomas, but they have a poorer outcome ( $p<0.05)$. Key Messages: Primary MSICHs are rare and share features with solitary intracerebral hemorrhage regarding age and the location and distribution of hematomas. Patients have a poorer prognosis but higher favorable outcome rates in case of survival. This information adds to the awareness of clinicians that higher rates of favorable outcomes can be achieved for MSICHs.

(C) 2014 S. Karger AG, Basel

\section{Introduction}

Intracerebral hemorrhage is an important clinical condition leading to severe disability and a high mortality rate. A rare type of stroke, even in the era of CT scanning, is that of multiple simultaneous intracerebral hemorrhages (MSICHs) [1]. Primary MSICHs are defined as two discrete primary intracerebral hemorrhages occurring simultaneously or within $24 \mathrm{~h}$ since the first identified intracerebral hemorrhage [1].

Ten to twenty percent of all strokes are spontaneous intracerebral hemorrhages [2, 3]. The incidence of MSICHs is up to $5.6 \%$ of all spontaneous intracerebral hemorrhages. However, MSICHs occur more commonly in a secondary form [1], and primary MSICHs have a much lower incidence varying from 0.75 to $3.0 \%$ of all cases of spontaneous intracerebral hemorrhage $[1,4]$. The overall outcome and prognosis are also poorer than with primary solitary intracerebral hemorrhages $[1,4]$.

Although primary MSICHs are a rare condition, sporadic case reports, case series and summaries of cases have continuously been published worldwide. In the details of these reports, cross-references, data duplication, missing data, and cases of secondary MSICHs and nonsimultaneous multiple intracerebral hemorrhages are to be found. Nevertheless, data on true primary MSICHs can be extracted from them. A pooled data analysis will show the benefit of having more accurate clinical features of MSICHs. Still, one major obstacle is constituted by the different objectives of the published articles, precluding the assessment of some of the case data.

Currently, there is no systematic review of primary MSICHs. Therefore, the present review sheds some light on this rare condition. We provide an outline for epidemiologic features of MSICHs as well as for clinical outcome. The present study aimed to review MSICHs systematically, to clarify the data on and analyze published cases of primary MSICHs since 1954 [5], and to analyze the location and distribution of hematomas as well as the age, sex and outcomes of patients with MSICHs.

\section{Materials and Methods}

The present review was prepared systematically in accordance with the Preferred Reporting Items for Systematic Reviews and Meta-Analyses guidelines. We conducted a PubMed search for articles with results from human studies, with no language restriction, that were registered between January 1950 and September 2013. The search yielded 677 articles. 
These 677 articles were screened for their title, abstract and keywords, identifying the relevance of their treatment of MSICHs and excluding duplicates and irrelevant articles. The included articles were case reports and case series on primary MSICHs, with part of the text or the full text in English and with identifiable data on the age, sex and outcome of patients. The aforementioned process yielded 24 articles which met the inclusion criteria. The reference lists of these 24 selected articles were inspected as well, yielding an additional 20 articles. In all, 44 articles - 27 full texts and 17 abstracts - were selected for our review. The remaining 653 articles were excluded.

\section{Case Eligibility}

There were 248 identifiable cases of MSICHs assessed in these 44 articles; 52 duplicates were identified and excluded. Another 91 cases were excluded for various reasons: 18 cases with multiple nonsimultaneous intracerebral hemorrhages, 25 cases with secondary MSICHs, and 48 cases with incomplete data on age, sex and outcome. The remaining 105 cases of primary MSICHs with complete data on age, sex and outcome were studied and analyzed in detail.

\section{Results}

\section{Epidemiologic Features and Location of the Hematomas}

A total of 35 articles (table 1) are from Asian countries: 26 articles are from East Asia, with 17 from Japan [4, 8-10, 13, 14, 16, 17, 30, 34, 36-39, 41, 42, 46], 6 from Korea [11, 12, $15,18,24,40]$ and 3 from Taiwan [19, 32, 35], and 9 articles are from other Asian countries, with 3 from India [20, 23, 29], 3 from Turkey [22, 25, 26], 2 from Iraq [28, 31] and 1 from Nepal [27]. The remaining 9 articles are from outside Asia: 1 from Serbia in Europe [21], 6 from the USA [1, 5-7, 43, 44], and 1 each from Cuba in the Caribbean [45] and Argentina in South America [33].

In the 105 selected cases, there were 216 hematomas distributed in both the supratentorial and the infratentorial regions. The supratentorial region was the location of 181 hematomas (83.80\%), distributed between the following brain areas: the lobar region (16 hematomas; $7.41 \%$ ), basal ganglia (99 hematomas; $45.83 \%$ ) and thalamus (66 hematomas; $30.56 \%$ ). The hematomas were found to be nearly equally distributed between the left and the right hemisphere, with 91 and 90 hematomas, respectively (fig. 1). The infratentorial region contained fewer hematomas $(n=35 ; 16.20 \%): 2(0.92 \%)$ in the midbrain, $11(5.09 \%)$ in the pons and $22(10.19 \%)$ in the cerebellum, as shown in figure 1.

The primary MSICHs could also be categorized into bilaterally located (56 cases; 112 hematomas) and nonbilaterally located hematomas (49 cases; 104 hematomas). Bilateral MSICHs were found in certain brain regions, i.e. the lobar region, basal ganglia, thalamus and cerebellum. Bilateral lobar hemorrhages were found in 1 case $(0.95 \%)$, in the bilateral occipital lobes, as reported in 1997 [13]. The most common area of bilateral MSICHs was the bilateral basal ganglia (table 2) with 35 cases (33.33\%); this was followed by bilateral thalamic hemorrhages, which were found in 19 cases $(18.10 \%)$. The cerebellum was the most common location of hematomas in the infratentorial region, but bilateral cerebellar hemorrhages were found in only 1 case (0.95\%), as reported recently in 2012 (table 2) [29].

Another category of MSICHs is the nonbilateral one. In the 49 cases of nonbilateral MSICHs, 6 cases had 3 hematomas and 43 cases had 2 hematomas (table 3). The total number of hematomas was 104 (table 3). They were found to be distributed between the following brain areas: the lobar region (14 hematomas), basal ganglia (29 hematomas), thalamus (28 hematomas), midbrain ( 2 hematomas), pons (11 hematomas) and cerebellum (20 hema- 
Laiwattana et al.: Primary Multiple Simultaneous Intracerebral Hemorrhages between

1950 and 2013: Analysis of Data on Age, Sex and Outcome

Table 1. Summary of the literature (case reports, case series and case summaries)

\begin{tabular}{|c|c|c|c|c|c|c|}
\hline \multirow[t]{2}{*}{ Authors } & \multirow[t]{2}{*}{ Year } & \multicolumn{3}{|l|}{ Cases } & \multirow[t]{2}{*}{ Type of text } & \multirow[t]{2}{*}{ Searching method } \\
\hline & & Identifiable & Eligible & Ineligible & & \\
\hline \multicolumn{7}{|l|}{ Case reports } \\
\hline Hartson [5] & 1954 & 1 & & $1^{\mathrm{a}}$ & title & electronic search \\
\hline Tucker et al. [6] & 1980 & 2 & & $2^{\mathrm{a}}$ & abstract & electronic search \\
\hline Hickey et al. [7] & 1983 & 2 & $\begin{array}{l}2 \text { (from Ohta and Yokota } \\
{[42] \text { ) }}\end{array}$ & & abstract & electronic search \\
\hline Tanikake et al. [8] & 1983 & 2 & $\begin{array}{l}1 \text { (from Ohta and Yokota } \\
{[42] \text { ) }}\end{array}$ & $1^{\mathrm{a}}$ & abstract & electronic search \\
\hline Sato et al. [9] & 1986 & 3 & 1 & $1^{\mathrm{a}} ; 1^{\mathrm{b}}$ & full text & hand search \\
\hline Kabuto et al. [10] & 1995 & 2 & 2 & & full text & electronic search \\
\hline Kim et al. [11] & 1995 & 1 & 1 & & abstract & hand search \\
\hline Joo et al. [12] & 1997 & 2 & 2 & & abstract & hand search \\
\hline Nakamura et al. [13] & 1997 & 1 & 1 & & abstract & electronic search \\
\hline Sunada et al. [14] & 1999 & 1 & 1 & & abstract & electronic search \\
\hline Lee et al. [15] & 1999 & 1 & 1 & & abstract & hand search \\
\hline Kohshi et al. [16] & 2000 & 2 & 2 & & full text & electronic search \\
\hline Kazui et al. [17] & 2001 & 1 & & $1^{\mathrm{c}}$ & full text & hand search \\
\hline Choi et al. [18] & 2005 & 1 & 1 & & full text & hand search \\
\hline Hsieh et al. [19] & 2006 & 1 & 1 & & full text & hand search \\
\hline Asimi et al. [20] & 2007 & 1 & 1 & & abstract & hand search \\
\hline \multicolumn{7}{|l|}{ Kuljic-Obradovic } \\
\hline et al. [21] & 2007 & 1 & & $1^{\mathrm{d}}$ & full text & electronic search \\
\hline Ozdemir et al. [22] & 2007 & 1 & 1 & & full text & electronic search \\
\hline \multicolumn{7}{|l|}{ Balasubramaniam } \\
\hline et al. [23] & 2007 & 1 & 1 & & full text & electronic search \\
\hline Kim and Cho [24] & 2008 & 1 & 1 & & full text & hand search \\
\hline Terzi et al. [25] & 2010 & 1 & 1 & & full text & electronic search \\
\hline Akar and Bayrak [26] & 2010 & 1 & 1 & & full text & hand search \\
\hline \multicolumn{7}{|l|}{ Lamichhane and } \\
\hline Paudel [27] & 2010 & 1 & 1 & & full text & hand search \\
\hline Amin et al. [28] & 2010 & 1 & 1 & & full text & hand search \\
\hline Lalla et al. [29] & 2012 & 1 & 1 & & full text & hand search \\
\hline Ohba et al. [30] & 2012 & 1 & 1 & & abstract & hand search \\
\hline Amin [31] & 2013 & 1 & 1 & & abstract & electronic search \\
\hline \multicolumn{7}{|l|}{ Case series } \\
\hline Lin et al. [32] & 1993 & 6 & $\begin{array}{l}1 \text { (from Perez et al. [45]); } \\
2 \text { (from Silliman et al. [43]) }\end{array}$ & $3^{\mathrm{a}}$ & abstract & electronic search \\
\hline Mauriño et al. [33] & 2001 & 4 & 4 & & full text & electronic search \\
\hline Shiomi et al. [34] & 2004 & 11 & & $11^{\mathrm{a}}$ & abstract & hand search \\
\hline Yen et al. [35] & 2005 & 10 & 10 & & full text & electronic search \\
\hline Sorimachi et al. [36] & 2007 & 9 & & $9^{a}$ & full text & electronic search \\
\hline Stemer et al. [1] & 2010 & 29 & & $15^{\mathrm{d}} ; 14^{\mathrm{a}}$ & full text & electronic search \\
\hline Takeuchi et al. [37] & 2011 & 20 & 20 & & full text & electronic search \\
\hline \multicolumn{7}{|l|}{ Case summaries } \\
\hline Miyasaka et al. [38] & 1982 & 20 & 2 & $16^{\mathrm{c}} ; 2^{\mathrm{a}}$ & full text & hand search \\
\hline Tanno et al. [4] & 1989 & 5 & 5 & & abstract & hand search \\
\hline Uno et al. [39] & 1991 & 9 & 8 & $\begin{array}{l}1^{\text {a }} \text { (from Ohta and } \\
\text { Yokota [42]) }\end{array}$ & abstract & hand search \\
\hline Bae et al. [40] & 1997 & 3 & & $3^{a}$ & abstract & hand search \\
\hline Imai [41] & 2000 & 10 & 6 & $4^{\mathrm{d}}$ & full text & electronic search \\
\hline Ohta and Yokota [42] & 2003 & 21 & 2 & $19^{b}$ & full text & hand search \\
\hline Silliman et al. [43] & 2003 & 7 & 1 & $6^{\mathrm{b}}$ & full text & electronic search \\
\hline Finelli [44] & 2006 & 3 & 1 & $2^{\mathrm{d}}$ & full text & electronic search \\
\hline Perez et al. [45] & 2009 & 18 & 1 & $1^{\mathrm{c}} ; 1^{\mathrm{d}} ; 15^{\mathrm{b}}$ & full text & electronic search \\
\hline Masayoshi et al. [46] & 2010 & 28 & 15 & $11^{\mathrm{b}} ; 2^{\mathrm{d}}$ & full text & hand search \\
\hline
\end{tabular}

\footnotetext{
a Incomplete data. ${ }^{\mathrm{b}}$ Duplicate case. ${ }^{\mathrm{c}}$ Nonsimultaneous. ${ }^{\mathrm{d}}$ Not primary hemorrhages.
} 


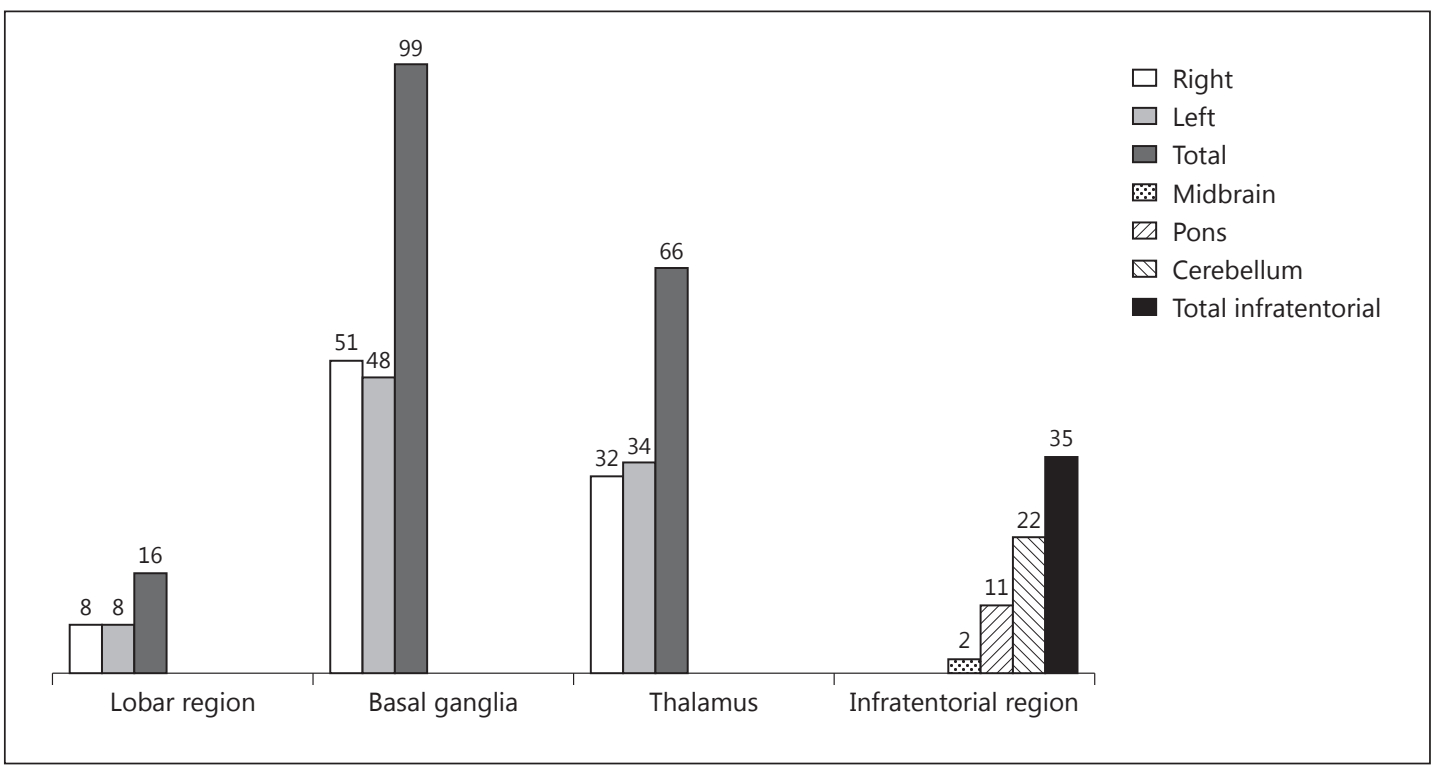

Fig. 1. Hematoma distribution (216 hematomas in 105 cases).

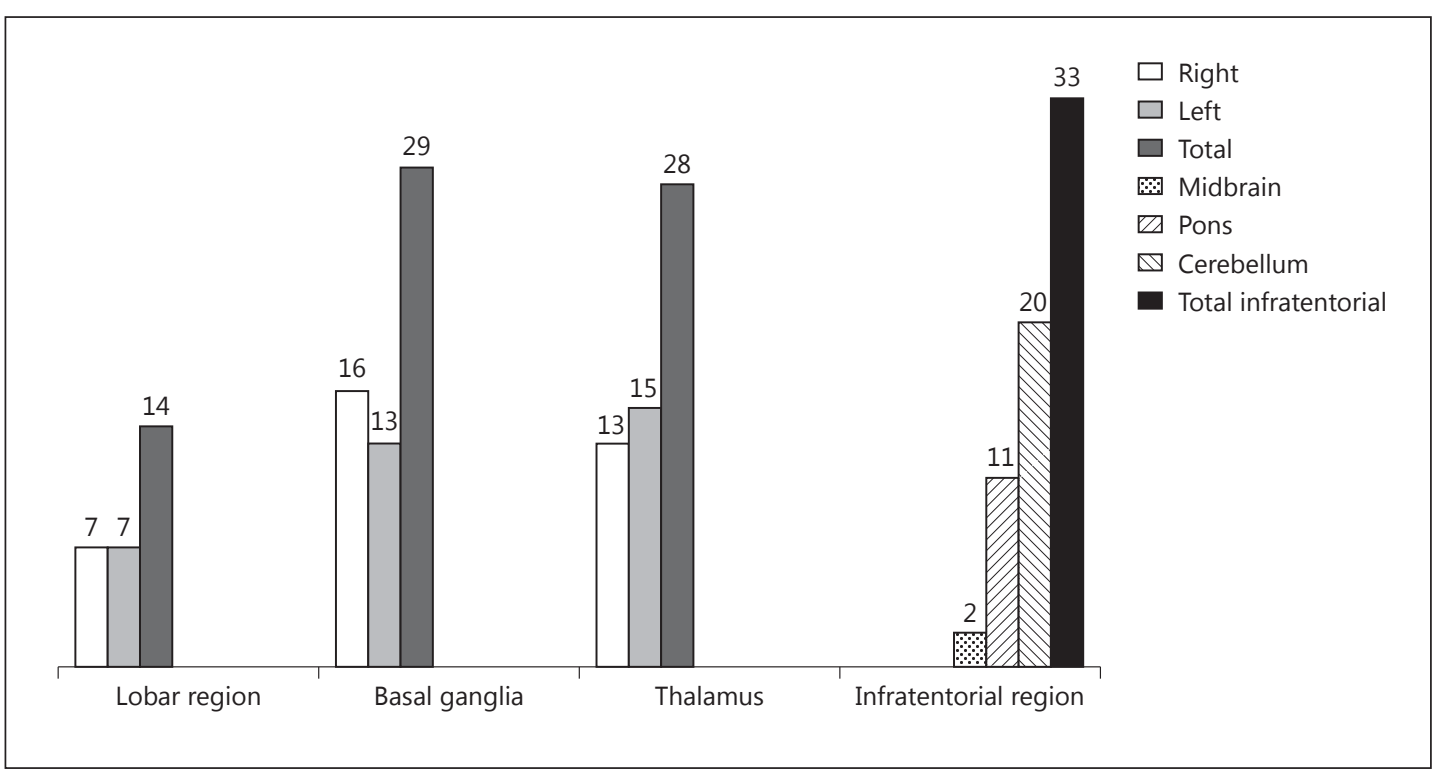

Fig. 2. Hematoma distribution of nonbilateral MSICHs (104 hematomas in 49 cases).

tomas). Although the name 'nonbilateral MSICHs' misleadingly suggests an uneven distribution of hematomas between the left and the right side of the brain, they were found to be nearly equally distributed, with 36 hematomas in the right hemisphere and 35 hematomas in the left (fig. 2).

The nonbilateral MSICHs were further categorized by hematoma location into those exclusively located in the supratentorial region, those exclusively located in the infratentorial region and those located in the combined supra-infratentorial region. The majority of the 


\section{Cerebirovascular \\ Diseases}

Table 2. Location of hematomas

\begin{tabular}{|c|c|c|}
\hline \multicolumn{3}{|l|}{ Cerebrovasc Dis Extra 2014;4:102-114 } \\
\hline DOI: $10.1159 / 000362111$ & \multicolumn{2}{|c|}{$\begin{array}{l}\text { (c) } 2014 \text { S. Karger AG, Basel } \\
\text { www.karger.com/cee }\end{array}$} \\
\hline \multicolumn{3}{|c|}{$\begin{array}{l}\text { Laiwattana et al.: Primary Multiple Simultaneous Intracerebral Hemorrhages betwee } \\
1950 \text { and 2013: Analysis of Data on Age, Sex and Outcome }\end{array}$} \\
\hline & $\begin{array}{l}\text { Cases, } \\
\mathrm{n}(\%)\end{array}$ & $\begin{array}{l}\text { Hematomas, } \\
\mathrm{n}(\%)\end{array}$ \\
\hline Bilateral lobar hemorrhages & $1(0.95)$ & $2(0.93)$ \\
\hline Bilateral basal ganglia hemorrhages & $35(33.33)$ & $70(32.40)$ \\
\hline Bilateral thalamic hemorrhages & $19(18.10)$ & 38 (17.59) \\
\hline Bilateral cerebellar hemorrhages & $1(0.95)$ & $2(0.93)$ \\
\hline Nonbilateral MSICHs & $49(46.67)$ & $104(48.15)$ \\
\hline Total & $105(100)$ & $216(100)$ \\
\hline
\end{tabular}

Table 3. Nonbilateral MSICHs

\begin{tabular}{lll}
\hline & $\begin{array}{l}\text { Cases, } \\
\mathrm{n}(\%)\end{array}$ & $\begin{array}{l}\text { Hematomas, } \\
\mathrm{n}(\%)\end{array}$ \\
\hline Total & $49(100)$ & $104(100)$ \\
Exclusively in supratentorial region & $19(38.78)$ & $41(39.42)$ \\
3 hematomas per case & 3 & 9 \\
2 hematomas per case & & \\
Basal ganglia and thalamus & 10 & 20 \\
Lobar region and thalamus & 3 & 6 \\
Lobar region and basal ganglia & 1 & 2 \\
Lobar region only & 1 & 2 \\
Ipsilateral caudate and putamen & 1 & 2 \\
Exclusively in infratentorial region & $2(4.08)$ & $4(3.85)$ \\
Pons and cerebellum & 2 & 4 \\
Combined supra-infratentorial region & $28(57.14)$ & $59(56.73)$ \\
3 hematomas per case & 3 & 9 \\
2 hematomas per case & & \\
Thalamus and cerebellum & 9 & 18 \\
Basal ganglia and pons & 6 & 12 \\
Basal ganglia and cerebellum & 6 & 12 \\
Lobar region and cerebellum & 2 & 4 \\
Basal ganglia and midbrain & 1 & 2 \\
Thalamus and pons & 1 & \\
\hline
\end{tabular}

nonbilateral MSICHs were in the combined supra-infratentorial region (28 cases; table 3); the combination of thalamus and cerebellum was the most common ( 9 cases). The combinations of basal ganglia and pons and of basal ganglia and cerebellum followed with 6 cases each. Other combinations included the lobar region and cerebellum ( 2 cases), the basal ganglia and midbrain ( 1 case), and the thalamus and pons ( 1 case). The remaining 3 cases had 3 hematomas each.

There were 19 cases of nonbilateral MSICHs exclusively in the supratentorial region. The most common combination there was that of basal ganglia and thalamus ( 10 cases). This was followed by the combination of the lobar region and thalamus ( 3 cases): 1 case each had hematomas in the lobar region and basal ganglia, in the lobar region only, and in the ipsilateral caudate and putamen. There were 3 cases with 3 hematomas each (table 3 ). There were 2 cases with hematomas found exclusively in the infratentorial region. Both had hematomas simultaneously in the pons and cerebellum (table 3). 


\section{Cerebrovascular \\ Diseases}

Table 4. Age range and average age of patients with MSICHs

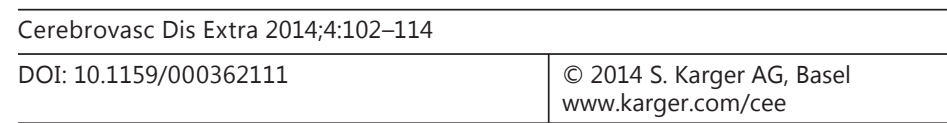

Laiwattana et al.: Primary Multiple Simultaneous Intracerebral Hemorrhages between 1950 and 2013: Analysis of Data on Age, Sex and Outcome

\begin{tabular}{lrll}
\hline & $\begin{array}{l}\text { Cases, } \\
\mathrm{n}\end{array}$ & $\begin{array}{l}\text { Age range, } \\
\text { years }\end{array}$ & $\begin{array}{l}\text { Average age } \\
\pm \text { SD, years }\end{array}$ \\
\hline Total & 105 & $28-94$ & $60.98 \pm 12.88$ \\
$\quad$ Males & 64 & $28-89$ & $59.13 \pm 12.49$ \\
$\quad$ Females & 41 & $33-94$ & $63.89 \pm 13.11$ \\
Bilateral lobar hemorrhages & 1 & & \\
$\quad$ Males & 1 & 55 & 55 \\
Bilateral basal ganglia hemorrhages & 35 & $35-89$ & $59.66 \pm 12.90$ \\
$\quad$ Males & 22 & $35-89$ & $59.95 \pm 12.87$ \\
$\quad$ Females & 13 & $40-89$ & $59.15 \pm 13.45$ \\
Bilateral thalamic hemorrhages & 19 & $28-82$ & $64.58 \pm 12.92$ \\
$\quad$ Males & 13 & $28-80$ & $59.92 \pm 12.68$ \\
$\quad$ Females & 6 & $68-82$ & $74.67 \pm 6.02$ \\
Bilateral cerebellar hemorrhages & 1 & & \\
$\quad$ Males & 1 & 38 & 38 \\
Nonbilateral MSICHs & 49 & $29-94$ & $61.12 \pm 12.69$ \\
$\quad$ Males & 27 & $29-80$ & $59.00 \pm 12.29$ \\
$\quad$ Females & 22 & $33-94$ & $63.73 \pm 12.96$ \\
\hline
\end{tabular}

\section{Age and Sex Distribution}

MSICHs were found to be more common in male patients $(60.95 \%)$. The male-to-female ratio was 1.56:1 (64:41; table 4). The 105 selected cases had an average age of $60.98 \pm 12.88$ years (range: 28-94 years). The males had a lower average age than the females: the average age of the male patients was $59.13 \pm 12.49$ years (range: $28-89$ years), whereas that of the female patients was $63.89 \pm 13.11$ years (range: $33-94$ years; table 4 ).

Bilateral lobar hemorrhages and bilateral cerebellar hemorrhages were encountered in 1 male patient each, aged 55 and 38 years, respectively. Bilateral basal ganglia hemorrhages were encountered in 22 males with ages ranging from 35 to 89 years and an average age of $59.95 \pm 12.87$ years, and in 13 females with ages ranging from 40 to 89 years and an average age of $59.15 \pm 13.45$ years (table 4). There were 19 cases of bilateral thalamic hemorrhages: 13 were males with ages ranging from 28 to 80 years and an average age of $59.92 \pm 12.68$ years, and 6 were females with ages ranging from 68 to 82 years and an average age of 74.67 \pm 6.02 years (table 4 ). The 49 cases of nonbilateral MSICHs included 27 males with ages ranging from 29 to 80 years and an average age of $59.00 \pm 12.29$ years and 22 females with ages ranging from 33 to 94 years and an average age of $63.73 \pm 12.96$ years (table 4 ).

\section{Outcome}

Although the outcome and prognosis of primary MSICHs are mentioned in the literature, i.e. a poor outcome and grave prognosis [4], they are not described in detail for this category. The present study shows the mortality rate to be $43.80 \%$ (46 of 105 cases) and the survival rate to be $56.20 \%$ (59 of 105 cases). The majority of the surviving patients $(40 ; 38.10 \%)$ had unfavorable outcomes, whereas the remaining 19 patients $(18.10 \%)$ had favorable outcomes. This reflects the high mortality rate and poor prognosis associated with MSICHs (table 5).

Both bilateral lobar hemorrhages and bilateral cerebellar hemorrhages had favorable outcomes. Bilateral basal ganglia hemorrhages had the highest mortality rate $(60 \% ; 21$ of 35 cases) and the worst prognosis. Approximately one third (34.29\%; 12 of 35 cases) had unfavorable outcomes; only $5.71 \%$ ( 2 of 35 cases) had favorable outcomes. The mortality rate for bilateral thalamic hemorrhages was $31.58 \%$ ( 6 of 19 cases). The survival rate was $69.42 \%$ 
Table 5. Outcome of MSICHs

\begin{tabular}{lrlrlr} 
& Cases, $\mathrm{n}$ & \multicolumn{2}{l}{ Survival, $\mathrm{n}$} & \multirow{2}{*}{ Death, $\mathrm{n}$} \\
\cline { 3 - 4 } & & favorable & unfavorable & \\
\hline Bilateral lobar hemorrhages & 1 & 1 & 0 & 0 \\
Bilateral basal ganglia hemorrhages & 35 & 2 & 12 & 21 \\
Bilateral thalamic hemorrhages & 19 & 4 & 9 & 6 \\
Bilateral cerebellar hemorrhages & 1 & 1 & 19 & 19 \\
Nonbilateral MSICHs & 49 & 11 & $40(38.10 \%)$ & $46(43.80 \%)$ \\
\hline Total & 105 & $19(18.10 \%)$ & 40 \\
\hline
\end{tabular}

Table 6. Relation of primary outcome and mortality to location of MSICHs ( $\chi^{2}$ test)

\begin{tabular}{lcll}
\hline & Cases, $\mathrm{n}$ & Outcome & Mortality \\
\hline Bilateral lobar hemorrhages & 1 & $0.033^{*}$ & 0.102 \\
Bilateral basal ganglia hemorrhages & 35 & $0.020^{*}$ & $0.018^{*}$ \\
Bilateral thalamic hemorrhages & 19 & 0.398 & 0.27 \\
Bilateral cerebellar hemorrhages & 1 & $0.033^{*}$ & 0.102 \\
Nonbilateral MSICHs & 49 & 0.278 & 0.331 \\
\hline Total & 105 & $0.000^{*}$ & 0.205 \\
\hline \multirow{2}{*}{$\mathrm{p}<0.05$} & & & \\
\hline
\end{tabular}

(13 of 19 cases); of these 19 cases, 4 (21.05\%) had favorable outcomes, while 9 (47.37\%) had unfavorable outcomes. The mortality rate for nonbilateral MSICHs was 38.78\% (19 of 49 cases); the remaining 30 patients (61.22\%) survived, of whom 19 (38.78\%) had unfavorable outcomes and $11(22.44 \%)$ had favorable outcomes.

Although the mortality rates were high, no statistical significance was found in the relationship between mortality rate and total MSICHs ( $p>0.05$ ). In contrast, prognosis showed a strong statistical significance regarding total MSICHs and poorer outcome $(\mathrm{p}<0.05)$. Bilateral basal ganglia hemorrhages were statistically significantly related to both poorer outcome and mortality ( $\mathrm{p}<0.05$; table 6$)$. On the other hand, both bilateral lobar and bilateral cerebellar hemorrhages were statistically significantly related to outcome, which was favorable in both cases, even though there was only 1 case per group. Bilateral thalamic hemorrhages and nonbilateral MSICHs were not statistically significantly associated with either mortality or prognosis.

\section{Discussion}

\section{Epidemiologic Features}

Stroke is a devastating condition with high rates of mortality and morbidity, ranking fourth among all causes of death, following heart diseases, cancer and chronic lower respiratory diseases [2]. The overall prevalence of stroke is approximately $3 \%$ in the general population [2]. Spontaneous intracerebral hemorrhages constitute $10-20 \%$ of all strokes [2, 3]. 
Primary intracerebral hemorrhages account for $75 \%$ of intracerebral hemorrhages. Primary intracerebral hemorrhages are intracerebral hemorrhages without an identifiable structural cause of the hemorrhage or acute insult to the vascular or coagulation system. Primary solitary intracerebral hemorrhages are more common in male patients, particularly those who are older than 55 years. People of Asian descent have a higher incidence of primary intracerebral hemorrhage [47].

MSICHs occur in $5.6 \%$ of spontaneous intracerebral hemorrhages [1]. A few studies have found the incidence of primary MSICHs to vary from $0.7-1.08 \%[4,32,46]$ to $2-3.4 \%[1,33]$ of primary intracerebral hemorrhages. Primary MSICHs have a much lower incidence than secondary MSICHs (3.4 and 13.6\%, respectively) [1]. The present study shows the prevalence of MSICHs in Asia, particularly in East Asia, Japan, Korea and Taiwan. According to our findings, 26 of 44 reports came from East Asia. This indirectly indicates a high incidence of MSICHs in Asian countries together with the incidence of primary intracerebral hemorrhages.

The first report of primary MSICHs was made on 1 case in the Bulletin of the Los Angeles Neurological Society in 1954 [5]. Unfortunately, only the title of this article could be accessed, and there was no additional information on the case. The earliest case of primary MSICHs with complete data was identified in 1977 [46]; in this case, the hemorrhages were found in the bilateral basal ganglia. Bilateral thalamic hemorrhages were first reported later, in 1981 [45]. There was only 1 case of bilateral lobar hemorrhages, which were found in the bilateral occipital lobes; this case was reported in 1997 [13]. The only case of bilateral cerebellar hemorrhages was recently reported in 2012 [29]. Nonbilateral primary MSICHs were first reported in 1982; they were a combination of basal ganglia and thalamic hemorrhages [38].

\section{Age and Sex Distribution}

Primary solitary intracerebral hemorrhages are more common in male patients and slightly younger female patients $[35,48]$. The present study shows an average age of 60.98 years for the 105 selected patients with primary MSICHs. MSICHs were more common in the male patients (64 cases; $60.95 \%$ ). The male-to-female ratio was $1.56: 1$. The female patients were found to be older than the male patients, with an average age of 63.89 versus 59.13 years. The age and sex distribution of primary MSICHs was found to be no different from that of primary solitary intracerebral hemorrhages.

\section{Location of Hematomas}

Primary solitary intracerebral hemorrhages commonly occur in the lobar region, basal ganglia, thalamus, brain stem and cerebellum [49]. Primary MSICHs have the same hematoma locations as primary solitary intracerebral hemorrhages [35, 46]. For MSICHs, the present study shows that the hematomas were most commonly located in the basal ganglia (45.83\%), followed by the thalamus (30.56\%), cerebellum (10.19\%), lobar region $(7.41 \%)$ and brain stem (6.31\%), including the midbrain and the pons.

Bilateral primary MSICHs were most commonly found in the basal ganglia (33.33\%). Bilateral thalamic hemorrhages were also commonly found (18.1\%), while bilateral lobar and cerebellar hemorrhages were least commonly encountered and have been identified in only 1 case each $(0.95 \%)$.

Nonbilateral primary MSICHs were encountered in $46.67 \%$ of the cases. The combinations of hematoma locations are ranked from most to least common, as follows: basal ganglia and thalamus ( 10 cases), thalamus and cerebellum ( 9 cases), basal ganglia and pons ( 6 cases), and basal ganglia and cerebellum ( 6 cases). Although the name 'nonbilateral primary MSICHs' suggests an unequal distribution of hematomas, these hematomas were found to be distributed in nearly equal numbers between the right and the left side of the individual locations. These 
findings confirm the conclusion that there is no preponderance of one side over the other for hematomas in nonbilateral primary MSICHs.

\section{Pathophysiologic Features}

The two main causes of primary intracerebral hemorrhage are hypertensive vasculopathy and cerebral amyloid angiopathy (CAA) $[3,50]$. Arterial hypertension was present in $75.6 \%$ of patients with spontaneous intracerebral hemorrhage and was proven to be a risk factor for it $[2,51,52]$. Nearly all the articles on primary MSICHs found the condition to be associated with hypertension. There were 2 articles that reported evidence for CAA in MSICHs: a study from 1980 reported 2 cases, but they were excluded from the study due to incomplete data on age, sex and outcome [6]; the other study found indirect evidence for amyloid angiopathy, i.e. a low cystatin C concentration in the cerebrospinal fluid [13]. Therefore, hypertension is one of the main diseases associated with primary MSICHs.

Hypertension and CAA have widespread effects on the cerebral vasculature and autoregulation mechanism. Chronic and long-standing hypertension causes hyperplastic arteriolosclerosis, leading to fragile vessels [35]. In CAA, $\beta$-amyloid protein deposition in the cerebral arteriolar smooth muscles causes a degeneration of the vessel wall, which leads to pressurepassive cerebral circulation and fragile vessels [53]. A detailed discussion of hypertensive vasculopathy and CAA is beyond the scope of this study but can be found elsewhere [53].

A few hypotheses have been made on possible mechanisms in the context of a widespread fragile cerebral vasculature and impaired autoregulation mechanism. In 1995, a first mechanism was proposed for the incidental simultaneous rupture of fragile vessels [4, 35]. A second possible mechanism was proposed a decade later in 2005 , suggesting that the initial hemorrhage causes a reflex increase in blood pressure and intracranial pressure, resulting in bleeding in other brain areas [18]. A third possible mechanism was proposed in 2011 and was similar to the second mechanism. With the hemorrhage-induced pain and coinciding release of catecholamines, hypertension worsens, thereby causing additional hemorrhage in diseased vessels [54]. In the end, the exact pathophysiology of primary MSICHs remains unclear.

\section{Outcome and Prognosis}

The prognosis of primary MSICHs was previously believed to be grave and worse than that of primary solitary intracerebral hemorrhage [35]. The mortality rate of patients with hemorrhagic stroke is reported to be very high at $37-44 \%$ and to vary with age $[2,55,56]$, which is comparable with our study, in which the overall death rate of patients with MSICHs was $43.80 \%$.

The occurrence of good functional outcomes is substantially reduced with primary intracerebral hemorrhage; only a small percentage of patients (11-12\%) achieves good functional outcomes $[2,57,58]$. The present study, however, shows the percentage of favorable outcomes to be as high as $18.10 \%$ for primary MSICHs. More intensive care might be required for patients with MSICHs to provide them with a better chance of having favorable outcomes.

However, there were some differences in prognosis and outcome between the subtypes of MSICHs; patients with bilateral basal ganglia hemorrhages, for instance, had the worst prognosis, the highest mortality rate $(60 \%)$ and the lowest percentage or favorable outcomes (5.71\%). These findings have statistical significance. Unfavorable outcomes were found to be most frequent in patients with bilateral thalamic hemorrhages (47.37\%), but there was no statistical significance.

\section{Secondary MSICHs}

To complete the present review, secondary MSICHs will be briefly discussed. Secondary MSICHs were found to be the most common type of simultaneous intracerebral hemorrhages, 
Laiwattana et al.: Primary Multiple Simultaneous Intracerebral Hemorrhages between

1950 and 2013: Analysis of Data on Age, Sex and Outcome

accounting for up to $13.6 \%$ of MSICHs [1]. Multiple etiologies have been suggested for secondary MSICHs. The most common cause is hematologic abnormalities [1]. Other etiologies include concomitant anticoagulant use, novel antithrombotic drug treatment, venous sinus thrombosis, vasculitis, cerebral metastasis and cardiopulmonary resuscitation [35, 59-61].

\section{Study Limitation and Future Direction}

The major limitation to the present study is the rarity of the condition under investigation, leading to unpublished or underdiagnosed cases. Although an exact account of its history, outcome and prognosis may not be completely achieved, the present paper has given an outline from the available published data.

An interesting topic is that MSICHs contain multiple hematomas inside the brain. These multiple simultaneous lesions in the brain may produce a different intracranial pressure in the area containing the hematomas, which may affect treatment options and outcomes. According to our study, favorable outcome rates are higher for MSICHs than for solitary intracerebral hemorrhages. From a modern neurologic perspective, neurologic intensive care and multimodal treatment may yield great benefit to patients with MSICHs, improving prognosis and outcome. A thorough study of the treatment options for and outcomes of MSICHs would provide optimal solutions with a high benefit to patients.

\section{Conclusions}

Primary MSICHs are a rare occurrence. However, sporadic cases have continuously been reported worldwide. The majority of case reports come from Asian countries. MSICHs have many features in common with solitary intracerebral hemorrhage, including age and sex distribution, location of hematomas and mortality rate. Cases with bilateral basal ganglia hemorrhages have the worst prognosis and the highest mortality rate, whereas cases with bilateral thalamic hemorrhages have the highest unfavorable outcome rate. According to the present study, MSICHs have higher favorable outcome rates than primary solitary intracerebral hemorrhages. The supratentorial region is the most common site of bleeding, and no preponderance of the right side over the left side has been discovered. Primary MSICHs in the infratentorial region tend to occur in the cerebellum.

\section{Disclosure Statement}

The authors declare no conflicts of interest.

\section{References}

1 Stemer A, Ouyang B, Lee VH, Prabhakaran S: Prevalence and risk factors for multiple simultaneous intracerebral hemorrhages. Cerebrovasc Dis 2010;30:302-307.

-2 Roger VL, Go AS, Lloyd-Jones DM, Benjamin EJ, Berry JD, Borden WB, et al: Heart disease and stroke statistics - 2012 update: a report from the American Heart Association. Circulation 2012;125:e2-e220.

-3 Feigin VL, Lawes CM, Bennett DA, Anderson CS: Stroke epidemiology: a review of population-based studies of incidence, prevalence, and case-fatality in the late 20th century. Lancet Neurol 2003;2:43-53.

4 Tanno H, Ono J, Suda S, Karasudani H, Yamakami I, Isobe K, et al: Simultaneous multiple hypertensive intracerebral hematoma: report of 5 cases and review of the literature. No Shinkei Geka 1989;17:223-228.

5 Hartson D: Multiple simultaneous primary intracerebral hemorrhages: report of a case. Bull Los Angel Neuro Soc 1954;19:174-177. 
Laiwattana et al.: Primary Multiple Simultaneous Intracerebral Hemorrhages between

1950 and 2013: Analysis of Data on Age, Sex and Outcome

6 Tucker WS, Bilbao JM, Klodawsky H: Cerebral amyloid angiopathy and multiple intracerebral hematomas. Neurosurgery 1980;7:611-614.

7 Hickey WF, King RB, Wang AM, Samuels MA: Multiple simultaneous intracerebral hematomas: clinical, radiologic, and pathologic findings in two patients. Arch Neurol 1983;40:519-522.

-8 Tanikake T, Kawaguchi S, Tada T, Kyoi K, Utsumi S, Nakasone K: Simultaneous, bilateral hypertensive intracranial hematomas. No Shinkei Geka 1983;11:1085-1090.

-9 Sato M, Tanaka S, Kohama A, Sone T, Fukunaga M, Morita R: Spontaneous bilateral intracerebral hemorrhage occurring simultaneously: case report. Neurol Med Chir (Tokyo) 1986;26:545-547.

10 Kabuto M, Kubota T, Kobayashi H, Nakagawa T, Arai Y, Kitai R: Simultaneous bilateral hypertensive intracerebral hemorrhages. Neurol Med Chir 1995;35:584-586.

11 Kim SH, Cho TH, Chung HS, Lee HK, Chu JW, Lee KC: A case of bilateral simultaneous hypertensive intracerebral hemorrhage in basal ganglia. J Korean Neurosurg Soc 1995;24:682-688.

12 Joo KS, Shin WH, Bae HG, Kim BT, Choi SK, Byun BJ: Simultaneous bilateral hypertensive intracerebral hemorrhages: report of two cases. J Korean Neurosurg Soc 1997;26:1436-1439.

-13 Nakamura K, Saku Y, Ibayashi S, Fujishima M: Simultaneous multiple brain hemorrhage associated with migraine: a case report. Angiology 1997;48:551-555.

14 Sunada I, Nakabayashi H, Matsusaka Y, Nishimura K, Yamamoto S: Simultaneous bilateral thalamic hemorrhage: case report. Radiat Med 1999;17:359-361.

15 Lee JK, Lee JH, Kim ES, Kim TS, Jung S, Kim JH, et al: Bilateral simultaneous hypertensive intracerebral hemorrhages in both thalami: a case report. Chonnam Med J 1999;35:431-436.

16 Kohshi K, Abe H, Tsuru E: Simultaneous hypertensive intracerebral hematomas: two case reports. J Neurol Sci 2000;181:137-139.

17 Kazui H, Mori E, Hashimoto M, Hirono N: Phobia after bilateral thalamic hemorrhage. Cerebrovasc Dis 2001; 12:283-284.

18 Choi JW, Lee JK, Kim JH, Kim SH: Bilateral simultaneous hypertensive intracerebral hemorrhages in both thalami. J Korean Neurosurg Soc 2005;38:468-470.

19 Hsieh CT, Tsai WC, Tsai DH, et al: Simultaneous multiple spontaneous intracerebral hemorrhages: a case report and literature review. Neuroradiol J 2006;19:220-222.

20 Asimi RP, Wani MA, Ahmad F: Bilateral simultaneous hypertensive intracerebral hemorrhage in both putamen. Ann Indian Acad Neurol 2007;10:272-273.

-21 Kuljic-Obradovic D, Labudovic G, Basurovic N, Savic M: Neuropsychological deficits after bithalamic hemorrhages. J Neurol Sci 2007;257:174-176.

22 Ozdemir O, Calisaneller T, Yildirim E, Altinors N: Simultaneous supra- and infratentorial hypertensive intracerebral haemorrhage. J Clin Neurosci 2007;14:775-777.

23 Balasubramaniam S, Nadkarni TD, Goel A: Simultaneous thalamic and cerebellar hypertensive haemorrhages. Neurol India 2007;55:183-184.

24 Kim YD, Cho YD: Multiple simultaneous hypertensive intracerebral hemorrhages in the pons and basal ganglia: a case report. Korean J Cerebrovasc Surg 2008;10:380-382.

25 Terzi M, Akkaya 0, Onar M: Pure sensory stroke due to bilateral basal ganglion hemorrhage: a case report. Turk Neurosurg 2010;20:406-408.

26 Akar H, Bayrak AO: A case report of bilateral subthalamic hemorrhages. Turk Noroloji Dergisi 2010;16:208210.

-27 Lamichhane D, Paudel R: Multiple simultaneous hypertensive supratentorial and infratentorial hemorrhages: a rare kind of hypertensive bleed. J Coll Med Sci Nepal 2010;6:53-56.

-28 Amin OS, Rasheed AH, Ahmed SM: Simultaneous intracerebral haemorrhages; which came first, the supratentorial or the infra-tentorial one? BMJ Case Rep 2010;2010:bcr0320102805.

29 Lalla R, Malhotra HS, Garg RK, Verma R: Conservative management in a rare case of spontaneous bilateral cerebellar haemorrhage. BMJ Case Rep 2012;2012:bcr2012006177.

30 Ohba S, Nakagawa T, Shimizu K, et al: Simultaneous bilateral thalamic hemorrhages in adults: case report and review of the literature. Chirurgia 2012;25:379-382.

-31 Amin OS: Simultaneous hypertensive intracerebral haemorrhages: what are the odds? BMJ Case Rep 2013; 2013:bcr2012008047.

-32 Lin CN, Howng SL, Kwan AL: Bilateral simultaneous hypertensive intracerebral hemorrhages. Gaoxiong Yi Xue Ke Xue Za Zhi 1993;9:266-275.

33 Mauriño J, Saposnik G, Lepera S, Rey RC, Sica RE: Multiple simultaneous intracerebral hemorrhages. Arch Neurol 2001;58:629-632.

-34 Shiomi N, Miyagi T, Koga S, Karukaya T, Tokutomi T, Shigemori M: Simultaneous multiple hypertensive intracerebral hematoma. No Shinkei Geka 2004;32:237-244.

-35 Yen CP, Lin CL, Kwan AL, Lieu AS, Hwang SL, Lin CN, et al: Simultaneous multiple hypertensive intracerebral hemorrhages. Acta Neurochir (Wien) 2005;147:393-399.

-36 Sorimachi T, Ito Y, Morita K, Fujii Y: Microbleeds on gradient-echo T2*-weighted MR images from patients with multiple simultaneous intracerebral haemorrhages. Acta Neurochir (Wien) 2007;149:171-176.

-37 Takeuchi S, Takasato Y, Masaoka H, Hayakawa T, Yatsushige H, Sugawara T: Simultaneous multiple hypertensive intracranial hemorrhages. J Clin Neurosci 2011;18:1215-1218. 
-38 Miyasaka Y, Nakayama K, Matsumori K, Beppu T, Kurata A, Satoh K, et al: Bilateral hypertensive intracerebral hemorrhage diagnosed by CT scan: report of five cases and review of literature. Neurol Med Chir (Tokyo) 1982;22:661-667.

- 39 Uno M, Hondo H, Matsumoto K: Simultaneous supra- and infratentorial hypertensive intracerebral hemorrhage. No Shinkei Geka 1991;19:933-938.

40 Bae HG, Doh JW, Lee KS, Yun IG, Byun BJ: Multiple simultaneous intracerebral hemorrhages: three case reports. J Korean Neurosurg Soc 1997;26:859-862.

41 Imai K: Bilateral simultaneous thalamic hemorrhages: case report. Neurol Med Chir (Tokyo) 2000;40:369371.

42 Ohta H, Yokota A: Multiple simultaneous hypertensive lobar hemorrhage. JJOMT 2003;51:378-382.

-43 Silliman S, McGill J, Booth R: Simultaneous bilateral hypertensive putaminal hemorrhages. J Stroke Cerebrovasc Dis 2003;12:44-46.

44 Finelli PF: A diagnostic approach to multiple simultaneous intracerebral hemorrhages. Neurocrit Care 2006; 4:267-271.

45 Perez J, Scherle C, Machado C: Subsequent bilateral thalamic haemorrhage. BMJ Case Rep 2009; 2009:bcr04.2009.1734.

46 Masayoshi N, Hiroyasu S, Yoshizumi D, et al: A case of simultaneous bilateral putaminal hemorrhage. J Jpn Coll Surg 2010;35:772-778.

47 Qureshi AI, Tuhrim S, Broderick JP, Batjer H, et al: Spontaneous intracerebral hemorrhage. N Engl J Med 2001; 344:1450-1460.

48 Petrea RE, Beiser AS, Seshadri S, Kelly-Hayes M, Kase CS, Wolf PA: Gender differences in stroke incidence and poststroke disability in the Framingham Heart Study. Stroke 2009;40:1032-1037.

49 Passero S, Ciacci G, Ulivelli M: The influence of diabetes and hyperglycemia on clinical course after intracerebral hemorrhage. Neurology 2003;61:1351-1356.

50 Hill MD, Silver FL, Austin PC, Tu JV: Rate of stroke recurrence in patients with primary intracerebral haemorrhage. Stroke 2000;31:123-127.

51 Sacco S, Marini C, Toni D, Olivieri L, Carolei A: Incidence and 10-year survival of intracerebral hemorrhage in a population-based registry. Stroke 2009;40:394-399.

$\$ 52$ Jackson CA, Sudlow CL: Is hypertension a more frequent risk factor for deep than for lobar supratentorial intracerebral haemorrhage? J Neurol Neurosurg Psychiatry 2006;77:1244-1252.

53 Thanvi B, Robinson T: Sporadic cerebral amyloid angiopathy: an important cause of cerebral haemorrhage in older people. Age Ageing 2006;35:565-571

54 Sonobe S, Fujimura M, Endo H, Inoue T, Shimizu H, Tominaga T: Subarachnoid hemorrhage due to ruptured posterior cerebral artery aneurysm simultaneously associated with multiple remote intracerebral hemorrhages. Neuro Med Chir (Tokyo) 2011;51:836-838.

55 Rosamond WD, Folsom AR, Chambless LE, Wang CH, McGovern PG, Howard G, et al: Stroke incidence and survival among middle-aged adults: 9-year follow-up of the Atherosclerosis Risk in Communities (ARIC) cohort. Stroke 1999;30:736-743.

56 El-Saed A, Kuller LH, Newman AB, Lopez 0, et al: Geographic variations in stroke incidence and mortality among older populations in four US communities. Stroke 2006;37:1975-1979.

57 Arboix A, Comes E, Garcia-Eroles L, Massons J, et al: Site of bleeding and early outcome in primary intracerebral hemorrhage. Acta Neurol Scand 2002;105:282-288.

58 Broderick JP, Brott T, Tomsick T, Miller R, et al: Intracerebral hemorrhage more than twice as common as subarachnoid hemorrhage. J Neurosurg 1993;78:188-191.

59 Cha KC, Thi TN, Shin HJ, Cha YS, Kim H, Lee KH, et al: Bilateral intracerebral hemorrhage following CPR. Signa Vitae 2012;7:53-55.

-60 Wendell LC, Freeman SH, Plotkin SR, Sim JR: Clinical reasoning: a case of multiple intracerebral hemorrhages. Neurology 2007;69:E30-E34.

61 Algin O, Ceylan G, Kilic E: An unusual cause of multiple cerebral hemorrhages: drotrecogin alpha (activated protein C). AJNR Am J Neuroradiol 2011;32:E85-E86. 